\title{
FORMATION OF DEEP GLACIAL INCISIONS DURING THE ELSTERIAN IN NW-EUROPE
}

More than 100 year ago German geologists encountered Quaternary deposits, deeply incised into Tertiary formations in the northern part of their country. As, in contrast to the Tertiary units, the incisions contained coarse sands containing good quality ground water these were unique targets for the extraction of drinking water. Although over the last century much information has been collected from boreholes, doubts remained over the mechanism responsible for the formation of the incisions.

During the seventies of the last century seismic exploration of the floor of the North Sea delivered another type of information on deep incisions. At first 2D seismic lines showed their depth and areal distribution. Later 3D surveys showed these same properties and, above that, the genetic structure of the sedimentary infill. However, in contrast to the situation on land data on the lithology of the infill were scarce.

In order to tie seismic data to lithologies an area in the North-Eastern part of the Netherlands was selected, in which a deep incision was expected to be present. The project was started with a Helicopter Electro-Magnetic Survey, in order to locate the incisions. By High Resolution Seismics a total of $13 \mathrm{~km}$ of seismic lines has been collected and processed. Finally boreholes provided lithological information at localities which were chosen based using the techniques just mentioned (BurVal Working Group, 2006). The interpretation of these data combined with earlier interpretations showed that a genetic interpretation for this type of incisions can not be based on the well known principle 'the present is the key to the past'. We have reconstructed the following stages in the formation of the deep incisions in the Northern Netherlands:

1. In a later stage of the glaciation large quantities of melt water are stored within the land ice. Eventually this water mass breaks through and in a, geologically speaking, extremely short period erodes a deep (up to 300-400 m) and wide (2-4 km) valley over a length of 40 to $60 \mathrm{~km}$. Erosion most probably starts subglacially, but, judged from the dimensions of the valley (especially the width), the ice will cave in soon after the formation starts.

2. While the raging melt waters continue to erode the subsoil in an upstream direction, sedimentation starts at the southernmost (downstream) end of the valley and fills it in a northerly direction. Due to the decrease in flow velocity a fining upward sequence is formed. In the Northern Netherlands the upper unit, many tenths of meters thick, consists of remarkably fine (130 mu) well sorted sands.

3. After the waning of the floods a lake remains, with a depth determined by the filling process of phase 2. In this lake thick sequences of fine-grained sediments (loam and clay) are formed. Although up to now not observed in the Netherlands in Northern Germany the land ice has moved forward locally after the erosion phase and has deposited tills and fluvioglacial sands in the depressions.

4. At the transition to the next interglacial stage the depressions are full in the province of Groningen. In the province of Friesland, situated more to the west, incisions are filled with younger marine deposits during the next interglacial stage.

The deep incisions have been formed during the later stages of the Elsterian. Infill with marine sediments took place in the Holsteinian. 